\title{
Application of CFD Codes in Nuclear Reactor Safety Analysis
}

\author{
T. Höhne, E. Krepper, and U. Rohde \\ Forschungszentrum Dresden-Rossendorf (FZD), Institute of Safety Research, P.O. Box 5101 19, D-01314 Dresden, Germany \\ Correspondence should be addressed to T. Höhne, t.hoehne@fzd.de
}

Received 16 January 2009; Accepted 29 June 2009

Academic Editor: Michel Giot

Copyright ( $\odot 2010$ T. Höhne et al. This is an open access article distributed under the Creative Commons Attribution License, which permits unrestricted use, distribution, and reproduction in any medium, provided the original work is properly cited.

\begin{abstract}
Computational Fluid Dynamics (CFD) is increasingly being used in nuclear reactor safety (NRS) analyses as a tool that enables safety relevant phenomena occurring in the reactor coolant system to be described in more detail. Numerical investigations on single phase coolant mixing in Pressurised Water Reactors (PWR) have been performed at the FZD for almost a decade. The work is aimed at describing the mixing phenomena relevant for both safety analysis, particularly in steam line break and boron dilution scenarios, and mixing phenomena of interest for economical operation and the structural integrity. For the experimental investigation of horizontal two phase flows, different non pressurized channels and the TOPFLOW Hot Leg model in a pressure chamber was build and simulated with ANSYS CFX. In a common project between the University of Applied Sciences Zittau/Görlitz and FZD the behaviour of insulation material released by a LOCA released into the containment and might compromise the long term emergency cooling systems is investigated. Moreover, the actual capability of CFD is shown to contribute to fuel rod bundle design with a good CHF performance.
\end{abstract}

\section{Introduction}

The last decade has seen an increasing use of three-dimensional CFD codes to predict steady state and transient flows in nuclear reactors because a number of important phenomena such as pressurized thermal shocks, coolant mixing, and thermal striping cannot be predicted by traditional one-dimensional system codes with the required accuracy and spatial resolution. CFD codes contain models for simulating turbulence, heat transfer, multiphase flows, and chemical reactions. Such models must be validated before they can be used with sufficient confidence in NRS applications. The necessary validation is performed by comparing model results against measured data. However, in order to obtain a reliable model assessment, CFD simulations for validation purposes must satisfy strict quality criteria given in the Best Practice Guidelines (BPGs).

Our partner for CFD code qualification is ANSYS CFX [1], which is one of the leading CFD codes worldwide. Based on this partnership the models developed are implemented into the code and thus contribute to the code qualification. In principle the presented simulation could be performed by any other actual CFD-code. The following topical issues, where CFD calculations have been performed, will be briefly discussed in the paper:

(1) coolant mixing,

(2) corizontal stratified flow phenomena in the Hot Leg of PWR,

(3) Debris transport phenomena in multidimensional water flow,

(4) sub-cooled boiling Application to fuel rod bundle safety assessment.

The material presented has been prepared by FZD partly under the sponsorship by the European Commission and the German Government (BMWi).

\section{Coolant Mixing}

Numerical investigations on coolant mixing in Pressurized Water Reactors (PWRs) have been performed by other institutes and at the FZD for more than a decade [2-9]. The work was aimed at describing the mixing phenomena relevant for both safety analysis, particularly in steam line 


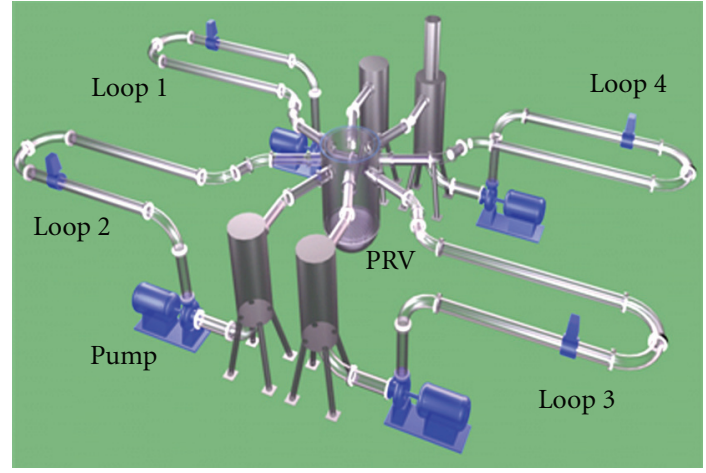

FIGURE 1: Scheme of ROCOM.

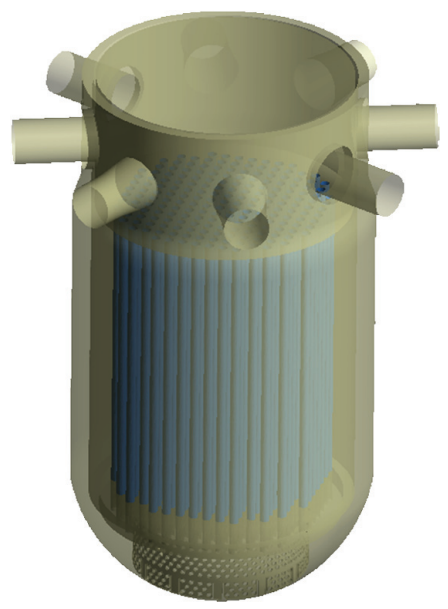

Figure 2: Grid model of ROCOM.

break and boron dilution scenarios, and mixing phenomena of interest for economical operation and the structural integrity.

With the setup of the ROCOM $[8,9]$ test facility (Figure 1), a unique database has been created to be used for the validation of Computational Fluid Dynamics (CFD) codes for the application to turbulent mixing in nuclear reactors. Benchmark problems based on selected experiments were used to study the effect of different turbulent mixing models under various flow conditions, to investigate the influence of the geometry, the boundary conditions, the grid, and the time step in the CFD analyses. In doing the calculations the Best Practice Guidelines for nuclear reactor safety calculations have been followed [5].

A selection of the performed work is described in [5]:

(i) stationary and transient flow and mixing studies of the coolant in the PWR Konvoi and the ROCOM test facility with CFX-4 and ANSYS CFX-5-11 during boron dilution transients (start-up of the first coolant pump), Figure 3,

(ii) main steam line break scenarios, Figure 4,

(iii) density driven flows after an inherent dilution with ECC injection (generic experiments at the ROCOM test facility) [7].

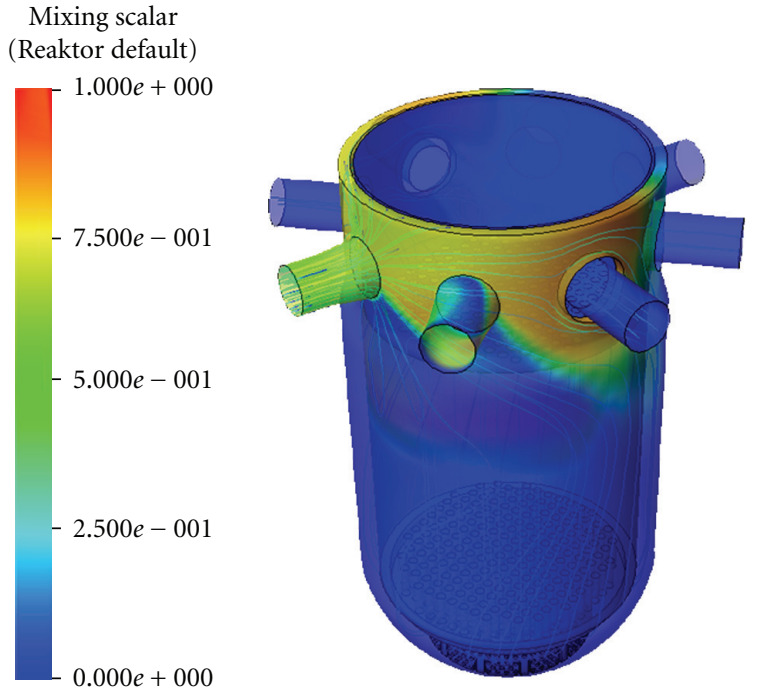

Figure 3: Pump Start-up.

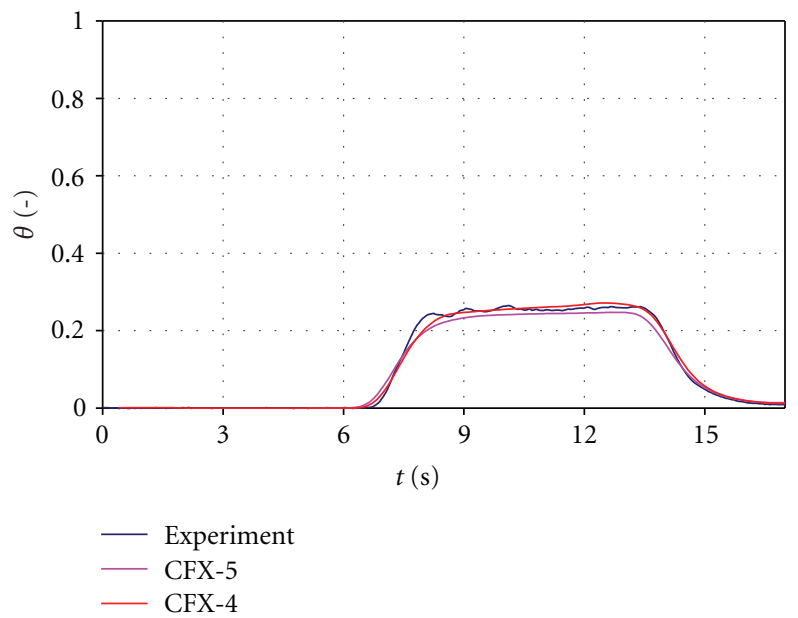

(a) Time dependent global averaged mixing scalar at the core inlet.

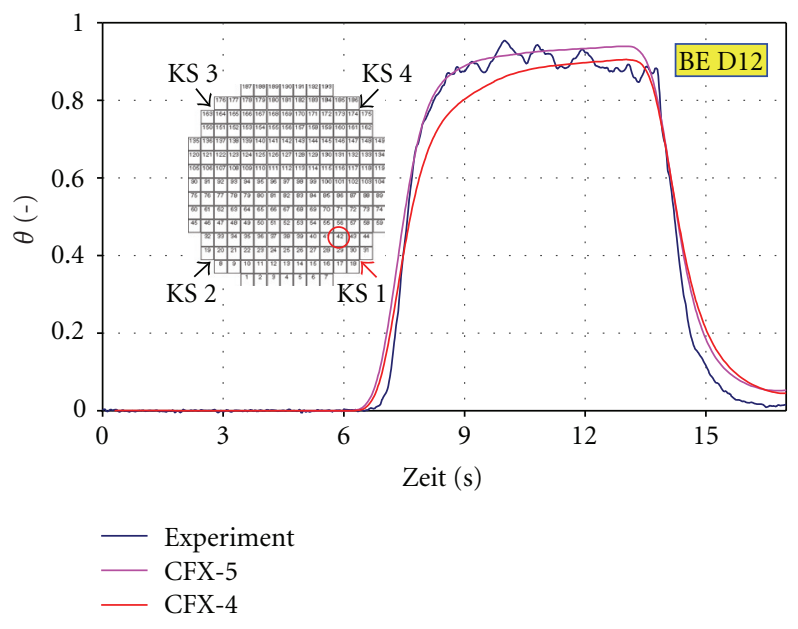

(b) Time dependent local mixing scalar at the core inlet, position near the wall.

Figure 4: Comparison of the measured and calculated mixing scalar (steady state flow field, $185 \mathrm{~m}^{3} / \mathrm{h}$ ). 


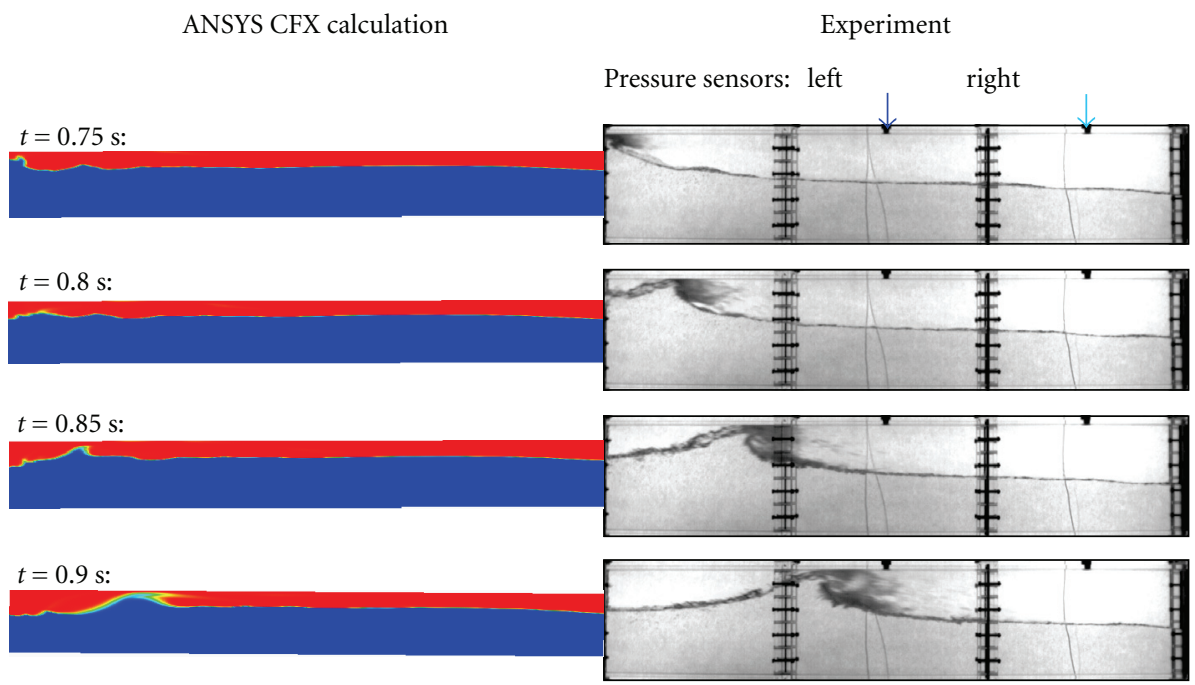

FIgURE 5: Comparative picture sequence of the recalculated slug.

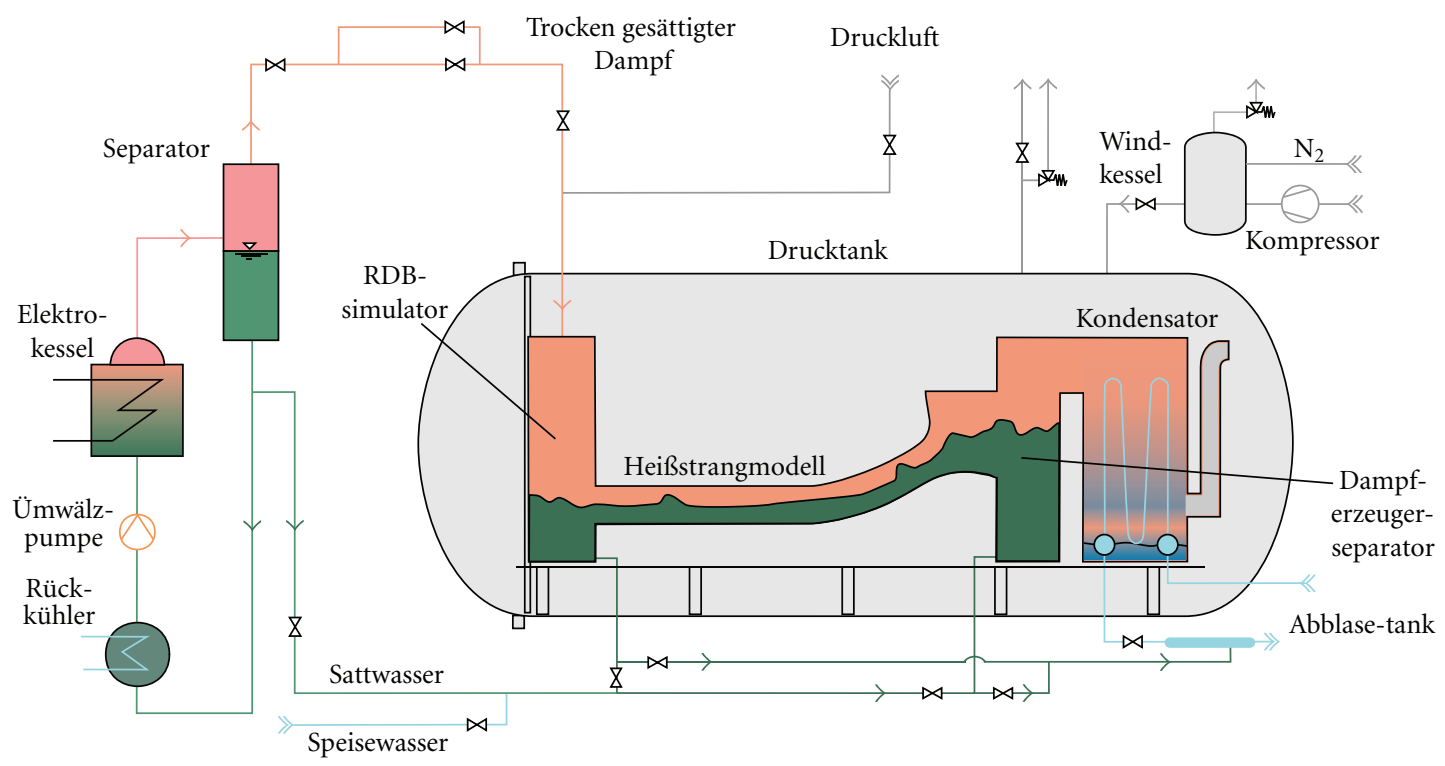

Figure 6: Scheme of the Hot Leg Model in the pressure chamber.

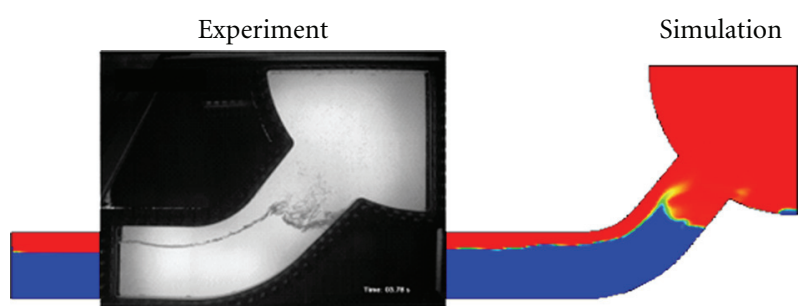

FIGURE 7: Snapshot of the results of the calculations.

The CFD calculations were carried out with the CFDcodes CFX-4 and CFX-5. Calculations were performed on the FZD LINUX cluster (operating system: Linux Scientific 64 bit, 32 AMD Opteron Computer Nodes, node configuration: $2 \times$ AMD Opteron $285(2.6 \mathrm{GHz}$, dual-core), 16 GB Memory). Using the block-structured code CFX-4 internals were modeled using the porous media approach and additional body forces. Sensitivity studies showed that the $k-\varepsilon$ turbulence model together with the second-order discretization scheme gives the best results. Within ANSYS CFX-5-11 it was possible to model all internals of the RPV of ROCOM in detail. A production mesh with 7 Million elements was generated (Figure 2). Detailed and extensive grid studies were made. It was shown that a detailed model of the perforated drum in CFX-5 gives the best agreement with the experiments. Sensitivity studies showed that the shear 


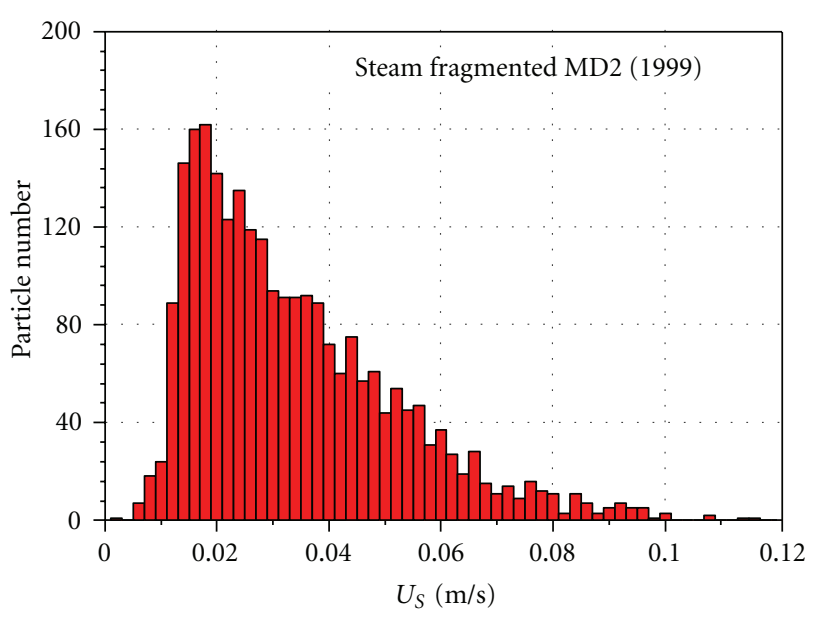

Figure 8: Distributions of the sinking velocities.

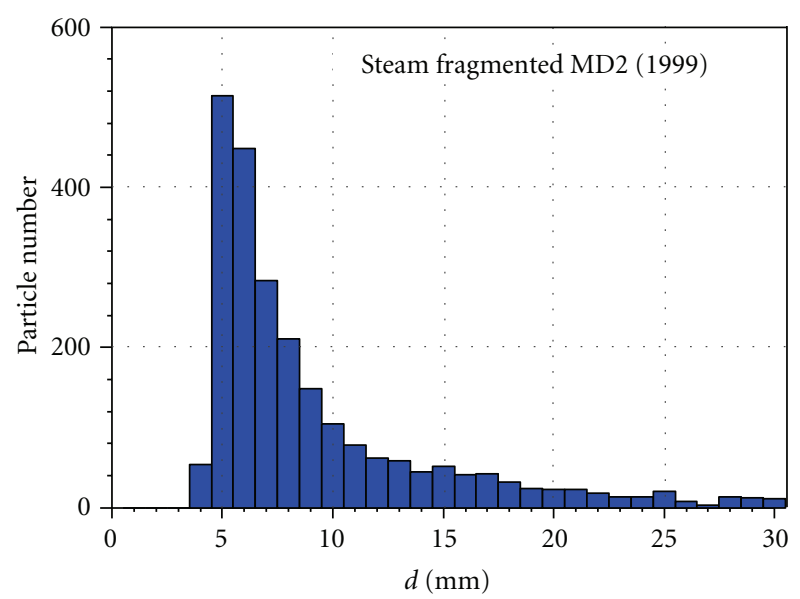

FIgURE 9: Distributions of the particle size.

stress transport (SST) turbulence model and the automatic wall functions together with higher-order discretization schemes should be used if possible (further details see [5]).

In the case of stationary mixing, the maximum value of the averaged mixing scalar at the core inlet was found in the sector below the inlet nozzle, where the tracer was injected (Figure 4). The mixing scalar is a dimensionless representation of the tracer concentration in the experiment or boron concentration/fluid temperature in reality. There is a good agreement between the measurement and the CFD calculations, especially in the averaged global mixing scalar at the core inlet. At the local position of the maximum mixing scalar the time course of the measurement and the calculations is also in good agreement (see Figure 4).

At the start-up case of one pump due to a strong impulse driven flow at the inlet nozzle the horizontal part of the flow dominates in the downcomer (Figure 3). The injection is distributed into two main jets; the maximum of the tracer concentration at the core inlet appears at the opposite part of the loop where the tracer was injected [6].

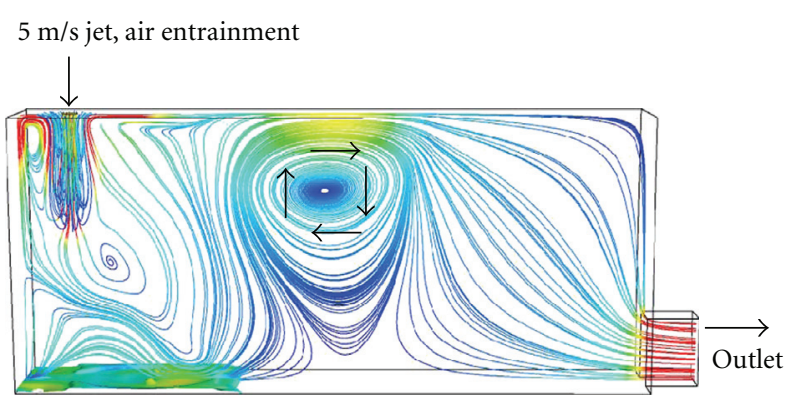

Deposited fiber material

FIgURE 10: Water flow field induced by the entrained air.

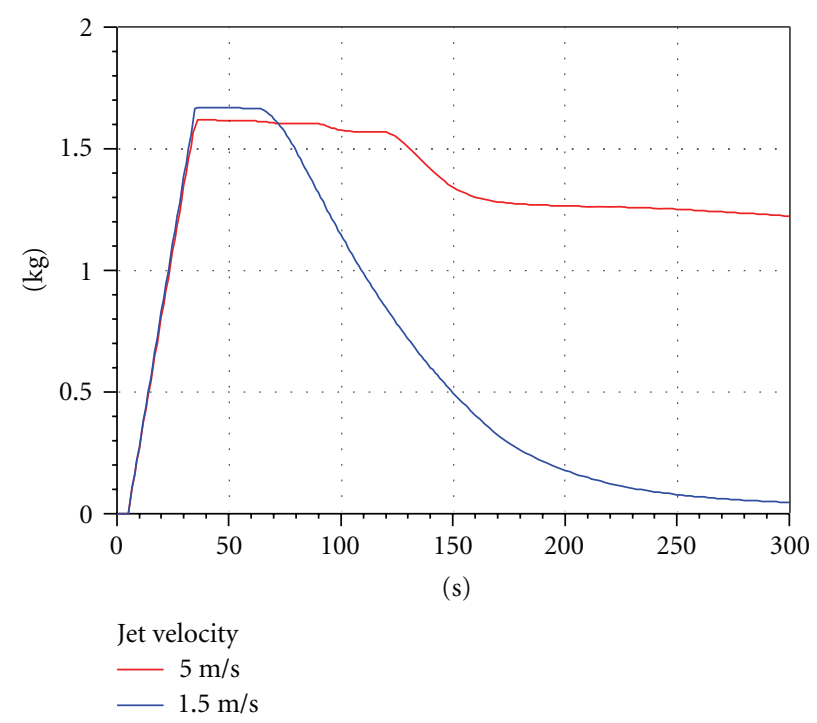

FIGURE 11: Accumulated fibre mass dependent on the inlet velocity.

\section{CFD-Simulations for Stratified Flows}

Slug flow as a multiphase flow regime can occur in the cold legs of pressurized water reactors, for instance, after a small break Loss of Coolant Accident (SB-LOCA). Slug flow is potentially hazardous to the structure of the system due to the strong oscillating pressure levels formed behind the liquid slugs. It is usually characterized by an acceleration of the gaseous phase and by the transition of fast liquid slugs, which carry out a significant amount of liquid with high kinetic energy. For the experimental investigation of air/water flows, a horizontal channel with rectangular cross-section was build at Forschungszentrum DresdenRossendorf (FZD) [10, 11]. Experimental data were used to check the feasibility to predict the slugging phenomenon with the existing multiphase flow models build in ANSYS CFX. Further it is of interest to prove the understanding of the general fluid dynamic mechanism leading to slug flow and to identify the critical parameters affecting the main slug flow parameters (like e.g., slug length, frequency and propagation velocity, pressure drop). For free surface simulations, the inhomogeneous multiphase model was used, where the gaseous and liquid phases can be partially 


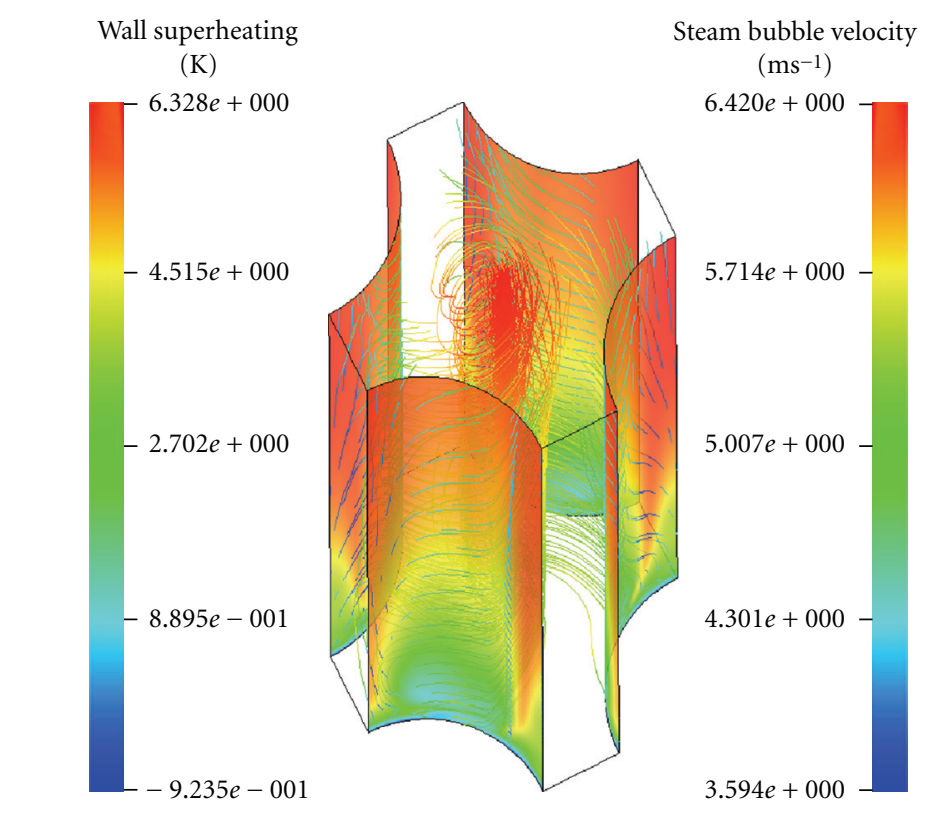

FIGURE 12: Hot channel vapour flow streamlines and rod surface temperatures.

mixed in certain areas of the flow domain. In this case the local phase demixing after a gas entrainment is controlled by buoyancy and interphase drag and is not hindered by the phase interface separating the two fluids. The fluiddependent shear stress transport (SST) turbulence models were selected for each phase. Damping of turbulent diffusion at the interface has been considered.

The picture sequence (see Figure 5) shows comparatively the channel flow in the experiment and in the corresponding CFD calculation. In both cases, a slug is developing. The tail of the calculated slug and the flow behind it is in good agreement with the experiment. The entrainment of small bubbles in front of the slug could is not be observed in the calculation. However, the front wave rolls over and breaks. This characteristic of the slug front is clearly to be seen in Figure 5. It is created due to the high air velocity.

Furthermore, pretest calculations CFD were carried out to simulate a slug current in a real geometry and under parameters relevant for the reactor safety. These calculations were performed for a flat model of the hot leg which represents the geometry of a $1: 3$ scaled Konvoi reactor (Figure 6). Steam and water were taken as a model fluid with a pressure of $50 \mathrm{bar}$ and the accompanying saturation temperature of $264^{\circ} \mathrm{C}$. To be able to perform the experiments at high pressure, the whole hot leg model is put into a pressure chamber.

The pretest calculations began with a partial water-full channel and quiescent gas phase. At the beginning of the steam supply the surface of the still standing water phase rises in the direction of the steam generator simulator. This effect is caused by the momentum exchange between flowing out steam and quiescent water. The calculation shows spontaneous waves which grow in the elbow to slugs originate in the horizontal part of the hot leg model. Figure 7 shows this state as a snapshot of the results of the calculations.

\section{Investigations of Insulation Fiber Transport Phenomena in Water Flow}

The investigation of insulation debris generation, transport, and sedimentation becomes more important with regard to reactor safety research for PWR and BWR, when considering the long-term behaviour of emergency core coolant systems during all types of loss of coolant accidents (LOCAs). The insulation debris released near the break during a LOCA incident consists of a mixture of disparate particle population that varies with size, shape, consistency, and other properties. Some fractions of the released insulation debris can be transported into the reactor sump, where it may perturb/impinge on the emergency core cooling systems [12-15].

Open questions of generic interest are the fibre transport in an aqueous flow, the sedimentation of the insulation debris in a water pool, its possible resuspension and transport in the sump water flow, and the fibre load on strainers and the corresponding pressure drop.

A joint research project on such questions is being performed in cooperation of the University of Applied Sciences in Zittau/Görlitz and the Forschungszentrum DresdenRossendorf. The project deals with the experimental investigation and the development of CFD models for the description of particle transport phenomena in coolant flow. While the experiments are performed at the University Zittau/Görlitz, the theoretical work is concentrated at Forschungszentrum Dresden-Rossendorf. Details were published by Krepper et al. in 2008 [16]. 
The main topics of the project are the following

(i) Primary particle constitution. Experiments are performed to blast blocks of insulation material by steam under the thermal hydraulic conditions to be expected during a LOCA incident (i.e., at pressures up to $11 \mathrm{MPa}$ ). The material obtained by this method is then used as raw material for further experiments.

(ii) Sedimentation of the fibres. The transport behaviour of the steam-blasted material is investigated in a water column by optical high-speed video techniques. The sinking velocities of the fibres are then used to derive the drag coefficients and other physical properties of the modelled fibre phase, which is necessary for the implementation of an adequate CFD simulation. Figures 7 and 8 show the measured distribution of sinking velocities and particle size for the insulation material MD2.

(iii) Transport of fibres in a turbulent water flow. For these investigations, a narrow channel with a racetrack type configuration was used with defined boundary conditions. Laser PIV measurements and high-speed video were used for the investigation of the water flow-field and the fibre concentration. Besides the drag acting on the particles, the turbulent dispersion force plays an important role in determining the momentum exchanged between the water and the fibrous phase.

(iv) Deposition and resuspension of fibres. The deposition and resuspension behaviour at low velocities was investigated by the same techniques and the narrow racetrack channel. Except that, in this case obstacles were inserted into the channel to change locally the flow regime. The experiments are designed to work with laser PIV measurement and high-speed video to investigate the fibre agglomeration in the obstacle region. CFD approaches consider the influence of the fibre material on the mixture viscosity and the dispersion coefficient on the transport of the solids.

(v) Effect of strainers. A test rig was used to study the influence of the insulation material loading on the pressure difference observed in the region of the strainers. A CFD model was developed that uses the approach of a porous body. The calculated differential pressure considers compactness of the porous fibre layer. Correlations from the filter theory known in chemical engineering are adapted to the certain fibre material properties by experiments. This concept enables the simulation of a partially blocked strainer and its influence on the flow field.

(vi) Behaviour of a plunging jet in a large pool and impact on fibre transport. By using high-speed video and laser (LDA and PIV) measurements, the progression of the momentum by the jet in the pool is investigated. Of special importance is the role that entrained gaseous bubbles play on disturbing the fluid and potentially influencing the fibre sedimentation and re-suspension. Figure 10 shows that under certain flow conditions the entrained air causes a swirl, which transports the injected fibres below the jet. In Figure 11 the fibre mass accumulated in the tank dependent on the inlet jet velocity is shown. In the case of only $1.5 \mathrm{~m} / \mathrm{s}$ a left turning swirl was found, and the fibre material was transported directly through the tank. For the other case of $5 \mathrm{~m} / \mathrm{s}$ jet velocity a right turning swirl occurred (see Figure 10), which deposited the fibres below the jet and accumulates fibres for longer time in the tank (see Figure 11).

\section{CFD-Calculation of a Hot Channel of a Fuel Rod Bundle}

Boiling is a very effective heat transfer mechanism. Liquid cooling including phase transfer very large heat fluxes can be established. Exceeding the critical heat flux, however, the heat transfer coefficient suddenly decreases, and the temperature increases leading to possible damaging of construction material. The critical heat flux depends not only on fluid properties but also on flow conditions and on geometric circumstances [17].

For the case of a fuel rod, the permissible heat flux can be influenced by the geometrical design. Especially the spacer grids equipped with mixing vanes play an important role to increase the permissible heat flux. The verification of design improvements and their influence on the critical heat flux require very expensive experiments. Therefore, the supplementation or even the replacements of expensive experiments by numerical analyses are of relevant interest in fuel assembly design.

Although the CFD modelling of critical heat flux is not yet able to accurately predict $\mathrm{CHF}$, the simulations shall demonstrate the capability of CFD supporting the fuel assembly design. In the calculations only subcooled boiling is simulated, which is here considered as a preliminary phenomenon towards departure of nucleate boiling (DNB). DNB might occur at the thermal hydraulic conditions of a PWR. A situation was investigated, when at full power and full pressure the inlet temperature rise caused undesired boiling in the channel.

A section of coolant channel between two spacer grids having a length of $z=0.5 \mathrm{~m}$ was simulated. The grid represents a subchannel between 4 rods having a diameter of $9 \mathrm{~mm}$ and a rod distance of $12.6 \mathrm{~mm}$. The thermal hydraulic and transport water properties were set for a pressure of 15.7 MPa, typical for PWR conditions. The heat flux at the rod surface was assumed to be $1.0 \cdot 10^{6} \mathrm{~W} / \mathrm{m}^{2}$, and the subcooling at the inlet was set to $12 \mathrm{~K}$ expecting the generation of vapour in the simulated section. The axial water velocity was set to $V_{Z}=5 \mathrm{~m} / \mathrm{s}$. The faces at the low and high $x$ respective at low and high $y$ were simulated as periodic boundary conditions, assuming that the channel is infinitely extended in these four directions.

The figure shows the flow condition in the considered channel section (axially shortened presentation). The mixing vanes generate a strong swirl in the actual calculation given 
as inlet condition. They are not modelled in this calculation, but a swirl was introduced into the flow as boundary condition at the inlet of the channel section. The overall vapour generation can be decreased by the swirl effect. Due to the centrifugal force, the heavier fluid componentthe water-is pushed outwards, whereas a large amount of the lighter component- the vapour-is accumulated in the centre of the channel. The streamlines show vapour bubbles moving in the centre of the channel caused by the centrifugal forces. The colours represent the temperatures of the metal surface. Their distribution can be used as qualitative criterion of the effect of a mixing vane. Further details were published by Krepper et al. (2007), [18].

\section{Capability of Actual CFD Codes}

The competiveness of CFD is continuously growing due the rapid developments in computer technology. However, computer capacity is still, and will be for a foreseeable future, a limiting factor for the capacity for CFD calculations to produce completely accurate results. Simplified models for describing turbulence therefore have to be used, and the computer capacity put restrictions on the resolution in space and time that one can use in a CFD calculation. This leads to modelling errors and numerical errors that give more or less inaccurate results. Validation of the quality and trust of different approaches in CFD calculations are therefore needed. So-called Best Practice Guidelines (BPGs) have to be used for quality assurance of the validation calculations (see Mahaffy et al., 2007 [19]). The BPGs are built on the concept of an error hierarchy. The different types of errors in CFD simulations are divided into the two main categories:

(i) numerical errors, caused by the discretisation of the flow geometry and the model equations, and by their numerical solution,

(ii) model errors, which arise from the approximation of physical processes by empirical mathematical models

This concept implies that numerical errors are quantified and reduced to an acceptable level, before comparison with experimental data is made. That means that the CFD solution has to be shown to be grid-independent, that is, results that do not change when the grid is refined further. A grid-independent solution can be defined as a solution that has a solution error that is within a range that can be accepted by the end-user, in view of the purpose of the calculations.

\section{Conclusion}

Computational Fluid Dynamics (CFD) is increasingly being used in nuclear community to model safety relevant phenomena occurring in the reactor coolant system. For this reason the long-term objective of the activities of the FZD R\&D program lies in the development of theoretical models for basic phenomena of transient, three-dimensional single and multiphase systems. Local geometry independent models for mass, momentum, heat transfer, and scalar transport are developed and validated. Such models are an essential precondition for the application of complex fluid dynamic codes to the modelling of flow related phenomena in nuclear facilities.

\section{Acknowledgments}

The work reported about in this paper was supported by the EU within the FLOMIX Project and the German Federal Ministry of Economics and Labour, Project no 150 1265, 1501270, and 1501307.

\section{References}

[1] ANSYS CFX User Manual, ANSYS-CFX, 2008.

[2] D. Alvarez, et al., "Three dimensional calculations and experimental investigations of the primary coolant flow in a $900 \mathrm{MW}$ PWR vessel," in Proceedings of the 5th International Topical Meeting on Nuclear Reactor Thermal Hydraulics (NURETH '92), vol. 2, pp. 586-592, 1992.

[3] F. Alavyoon, B. Hemström, N. G. Andersson, and R. Karlsson, "Experimental and computational approach to investigating rapid boron dilution transients in PWRs," in Proceedings of the CSNI Specialist Meeting on Boron Dilution Reactivity Transients, State College, Pa, USA, October 1995.

[4] B. Woods, UM $2 \times 4$ loop experimental findings on the effect of inertial and buoyancy forces on annular flow mixing for rapid boron dilution transients, Ph.D. thesis, University of Maryland, Baltimore, Md, USA, 2001.

[5] U. Rohde, T. Höhne, S. Kliem, et al., "Fluid mixing and flow distribution ín a primary circuit of a nuclear pressurized water reactor-validation of CFD codes," Nuclear Engineering and Design, vol. 237, no. 15-17, pp. 1639-1655, 2007.

[6] G. M. Cartland Glover, T. Höhne, S. Kliem, U. Rohde, F.-P. Weiss, and H.-M. Prasser, "Hydrodynamic phenomena in the downcomer during flow rate transients in the primary circuit of a PWR," Nuclear Engineering and Design, vol. 237, no. 7, pp. 732-748, 2007.

[7] T. Höhne, S. Kliem, and U. Bieder, "Modeling of a buoyancydriven flow experiment at the ROCOM test facility using the CFD-codes CFX-5 and TRIO_U," Nuclear Engineering and Design, vol. 236, no. 12, pp. 1309-1325, 2006.

[8] U. Rohde, S. Kliem, T. Höhne, et al., "Fluid mixing and flow distribution in the reactor circuit-part 1: measurement data base," Nuclear Engineering and Design, vol. 235, pp. 421-443, 2005.

[9] H.-M. Prasser, G. Grunwald, T. Höhne, S. Kliem, U. Rohde, and F.-P. Weiss, "Coolant mixing in a PWR-deboration transients, steam line breaks and emergency core cooling injection -experiments and analyses," Nuclear Technology, vol. 143 , pp. 37-56, 2003.

[10] C. Vallee, T. Höhne, H.-M. Prasser, and T. Sühnel, "Experimental investigation and CFD simulation of horizontal air/water slug flow," Kerntechnik, vol. 71, no. 3, pp. 95-103, 2006.

[11] T. Höhne, C. Vallee, and H.-M. Prasser, "Experimental and numerical prediction of horizontal stratified flows," in Proceedings of the International Conference on Multiphase Flow (ICMF '07), Leipzig, Germany, July 2007, paper no. S5_Tue_C_23. 
[12] "Knowledge base for emergency core cooling system recirculation reliability," NEA/CSNI/R(95) 11.

[13] "Knowledge Base for the Effect of Debris on Pressurized Water Reactor Emergency Core Cooling Sump Performance," NUREG/CR-6808; LA-UR-03-0880.

[14] "Knowledge Base for Strainer Clogging-Modifications Performed in Different Countries Since 1992," NEA/CSNI/R(2002)6.

[15] "Debris impact on Emergency coolant recirculation," in Proceedings of the OECD Workshop, Albuquerque, NM, USA, February 2004, NEA no. 5468.

[16] E. Krepper, G. Cartland-Glover, A. Grahn, et al., "Numerical and experimental investigations for insulation particle transport phenomena in water flow," Annals of Nuclear Energy, vol. 35, pp. 1564-1579, 2008.

[17] H. Anglart, O. Nylund, N. Kurul, and M. Z. Podowski, "CFD prediction of flow and phase distribution in fuel assemblies with spacers," Nuclear Engineering and Design, vol. 177, no. 13, pp. 215-228, 1997.

[18] E. Krepper, B. Koncar, and Y. Egorov, "Modelling of subcooled boiling - concept, validation and application to fuel assembly design," Nuclear Engineering and Design, vol. 237, pp. 716-731, 2007.

[19] J. Mahaffy, et al., "Best practice guidelines for the use of CFD in nuclear reactor safety applications," NEA/CSNI/R(2007)5, May 2007. 

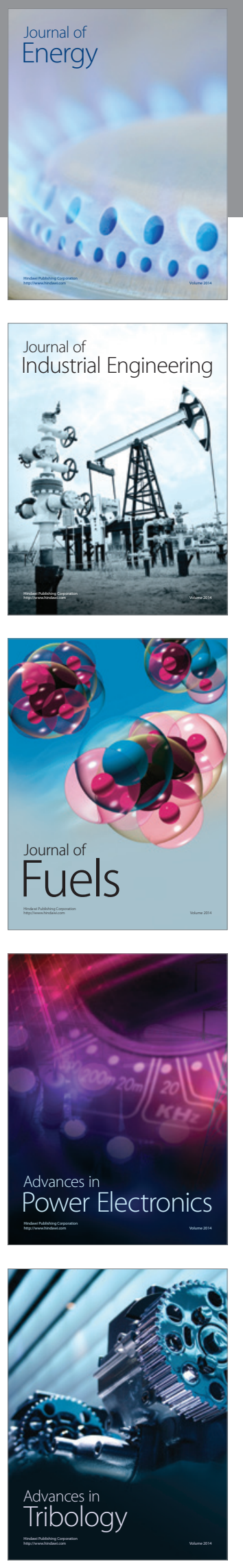
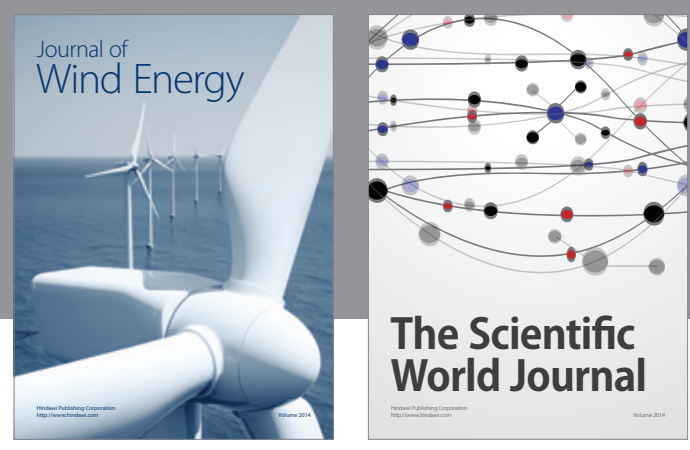

The Scientific World Journal

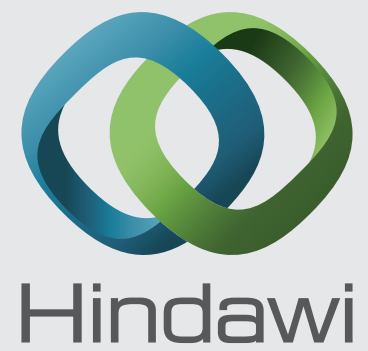

Submit your manuscripts at http://www.hindawi.com
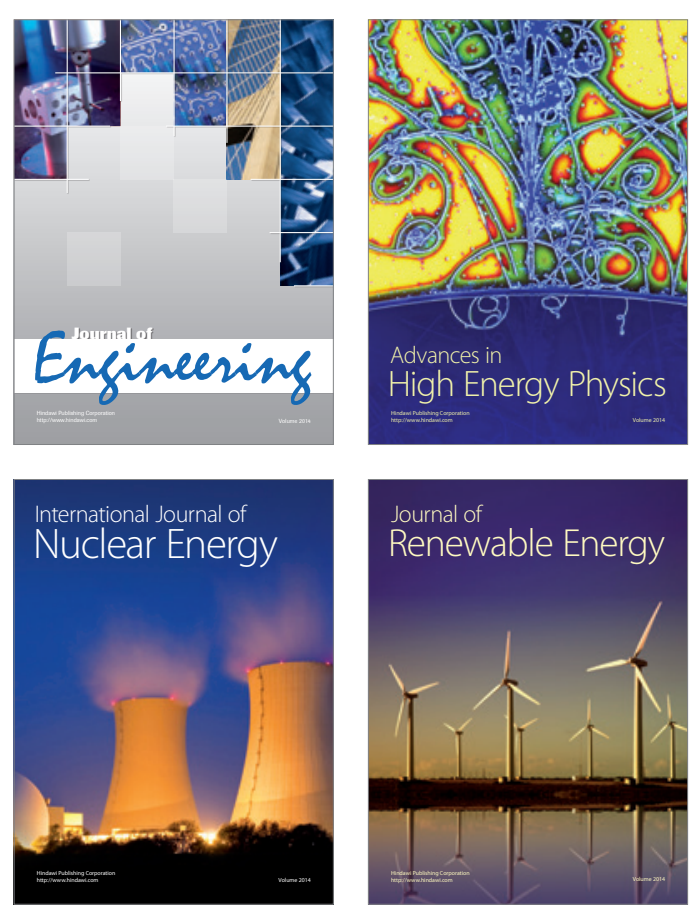

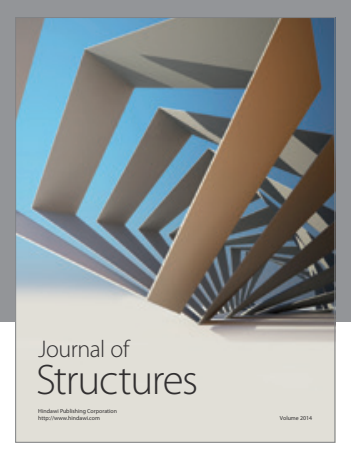

Rotating
Mechinery
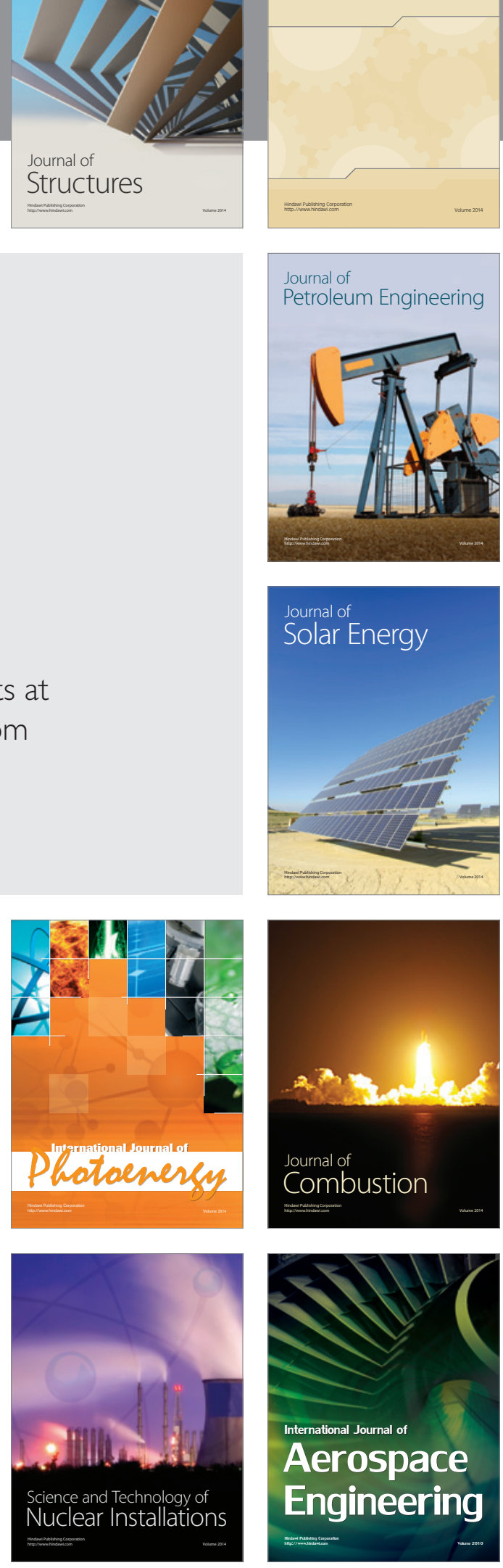